\title{
miR-130b suppresses the invasion and migration of prostate cancer via inhibiting DLL1 and regulating the PI3K/Akt pathways
}

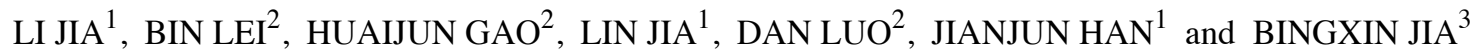 \\ ${ }^{1}$ Department of Oncology, The Third Hospital of Mianyang (Sichuan Mental Health Center), \\ Mianyang, Sichuan 621000; Departments of ${ }^{2}$ General Surgery and ${ }^{3}$ Urology Surgery, \\ Yulin Traditional Chinese Medicine Hospital, Yulin, Shaanxi 719000, P.R. China
}

Received August 16, 2018; Accepted December 3, 2019

DOI: $10.3892 /$ etm.2021.11021

\begin{abstract}
Prostate cancer occurs in the prostatic epithelium and poses a threat to the health of middle-aged and older males. The objective of the present study was to explore the roles of microRNA (miRNA/miR)-130b in prostate cancer and potential molecular mechanisms in order to control the migration and invasion of prostate cancer. For this purpose, reverse transcription-PCR was performed to evaluate the mRNA levels of DLL1, phosphoinositide-3 kinase (PI3K), protein kinase B (Akt) and matrix metalloproteinase (MMP)9, and western blot analysis was carried out to detect the protein expression levels of DLL1, phosphorylated (p)-PI3K, p-Akt and MMP9. A Transwell assay was conducted to examine the invasion rate of prostate cancer cells. Furthermore, a scratch wound assay was performed to examine the migration rate of prostate cancer cells. A luciferase assay was performed to examine the interaction between miRNA and its target mRNA. The results revealed that miR $-130 \mathrm{~b}$ had abnormal (low) expression in tumor tissues compared with that in the adjacent normal tissue. An miR-130b mimic suppressed the expression of DLL1. The expression of p-PI3K, p-Akt and MMP9 in prostate cancer cells transfected with the miR-130b mimic was decreased in comparison to the negative control and control groups. Furthermore, migration and invasion were significantly suppressed in the miR-130b mimic group. In conclusion, a novel pathway interlinking miR-130b and MMP9, p-Akt and p-PI3K, which regulates the migration and invasion of prostate cancer cells, was identified. These findings provide an intriguing biomarker and treatment strategy for patients with prostate cancer.
\end{abstract}

Correspondence to: Dr Bingxin Jia, Department of Urology Surgery, Yulin Traditional Chinese Medicine Hospital, 131 Xinjiannan Road, Yulin, Shaanxi 719000, P.R. China E-mail: dr_bingxinjia@aliyun.com

Key words: prostate cancer, miR-130b, Delta-like 1, phosphoinositide 3 kinase/protein kinase B, matrix metalloproteinase 9

\section{Introduction}

Prostate cancer occurs in the prostatic epithelium and poses a threat to the health of middle-aged and older males (1). After lung cancer, prostate cancer is the second most common malignant tumor affecting men in numerous western countries (2). Although the prostate cancer mortality rate in China is lower than that in western countries, the incidence has gradually increased (3). It is therefore necessary to explore novel molecular mechanisms for prostate cancer treatment.

MicroRNAs (miRNAs/miR) are a large class of endogenous non-coding single chain small molecule RNAs (20-25 nt) (4,5). Bioinformatics shows that miRNAs, when specifically combined with target gene mRNAs, can control hundreds of transcriptional target genes, thus promoting degradation or inhibiting translation (6). miRNAs may affect multiple pathways, thus altering the expression levels of the target mRNA and regulating the signaling pathways of target genes during the occurrence and development of tumors (7). miRNA expression profiles which vary depending on tumor type, play a crucial role in early diagnosis and prognosis as well as being molecular markers in cancer treatment (8). miRNA expression is abnormal in various tumors (9). miRNAs play a role as oncogenes or tumor suppressor genes $(4,10)$. miR-130b inhibits migration and invasion in breast cancer (11). Exploring the relationship between miRNA and prostate cancer may provide new therapies for its treatment.

Delta-like 1 (DLL1), as a canonical ligand of Notch signaling, participates in cell fate determination, cellular differentiation and pattern formation (12). Overexpressed DLL1 contributes to the progression of choriocarcinoma and hepatocellular carcinoma, while downregulated DLL1 promotes the apoptosis and suppresses the proliferation of multiple glioma cells (13-15). In prostate cancer, DLL1 was overexpressed in LNCaP, but decreased DLL1 promotes the lateral motility of PC-3 cells (16). The roles of DLL1 in prostate cancer is intriguing and the effects of DLL1 on the progression of prostate cancer has not been fully elucidated.

Phosphatidylinositol 3 kinase (PI3K)-protein kinase $\mathrm{B}$ (Akt)-mammalian target of rapamycin (mTOR) is one of three major signaling pathways in cancer. mTOR is a key kinase downstream of PI3K/Akt, which regulates tumor cell proliferation, growth, survival and angiogenesis (17-19). Cancer 
cells may escape detection and normal biochemical systems regulating the balance between apoptosis (programmed cell death) and survival (20). PI3K-Akt-mTOR generally promotes survival via the inhibition of proapoptotic factors and activation of anti-apoptotic factors (21). Previous studies suggest that the PI3K-Akt-mTOR signaling pathway plays an important role in cancer recurrence and metastasis (22-24).

In the present study, the roles of miR-130b in prostate cancer were investigated. It was found that miR-130b regulated migration and invasion of prostate cancer cells via the PI3K-Akt-mTOR axis.

\section{Materials and methods}

Tissue sample collection. A total of 30 prostate cancer tissues and 30 para-carcinoma tissues were obtained from patients (56-87 years; average age, 71 years) diagnosed with prostate cancer at Yulin Traditional Chinese Medicine Hospital Yulin, China from September, 2015 to January, 2017. The tissue samples were preserved in liquid nitrogen at $-80^{\circ} \mathrm{C}$. Informed consent was obtained from all patients. The present study was approved by the Ethics Committee of Yulin Traditional Chinese Medicine Hospital.

Cell culture. The prostate cancer cell line C4-2B was obtained from the American Type Culture Collection. The cells were incubated at $37^{\circ} \mathrm{C}$ and cultured in RPMI-1640 medium (Gibco; Thermo Fisher Scientific, Inc.) including $10 \%$ fetal bovine serum (FBS; HyClone; GE Healthcare Life Sciences) as well as $100 \mathrm{U} / \mathrm{ml}$ penicillin and $100 \mu \mathrm{g} / \mathrm{ml}$ streptomycin (Invitrogen; Thermo Fisher Scientific, Inc.). The incubator was humidified with $5 \% \mathrm{CO}_{2}$. Cell propagation was conducted every other day. Cells in the logarithmic $(\log )$ phase were used for experimentation.

Reverse transcription-quantitative PCR (RT-qPCR). Total RNA was extracted with TRIzol (Invitrogen; Thermo Fisher Scientific, Inc.) according to the manufacturer's protocol. miRNAs were extracted with a miRNeasy Mini kit (Qiagen, Inc.). Thereafter, a Primer-Script ${ }^{\mathrm{TM}}$ One Step RT-qPCR kit (Takara Biotechnology, Co., Ltd.) was used for cDNA synthesis at $50^{\circ} \mathrm{C}$. qPCR was performed to amplify the cDNA template using a SYBR ${ }^{\circledR}$ Premix Dimmer Eraser kit (Takara Biotechnology Co., Ltd.), according to the manufacturer's protocol. The PCR process was as follows: Denaturing for $5 \mathrm{~min}$ at $95^{\circ} \mathrm{C}$ and $4010-\mathrm{sec}$ cycles at $95^{\circ} \mathrm{C}$ and $1 \mathrm{~min}$ at $60^{\circ} \mathrm{C}$. GAPDH was used as a loading control for DLL1, PI3K, AKT and matrix metalloproteinase (MMP)9, and mRNA values were normalized against GAPDH. The expression of U6 acted as an internal control for miR-130b. Expression was quantified using the $2^{-\Delta \Delta C q}$ method (25). The primer sequences were as follows: DLL1 forward, 5'-TGCTCC GAAACAAGAGTGTG-3' and reverse, 5'-CAGGCAGAG CAGGTGATACA-3'; MMP9 forward, 5'-CAGAGATGCGTG GAGAGT-3' and reverse, 5'-TCTTCCGAGTAGTTTTGG-3'; miR-130b forward, 5'-GCCGCCAGTGCAATGATGAA-3' and reverse, 5'-GTGCAGGGTCCGAGGT-3'; U6 forward, 5'-CGC TTCGGCAGCACATATACTA-3' and reverse, 5'-CGCTTC ACGAATTTGCGTGTCA-3'; GAPDH forward, 5'-TGAAGG TCGGAGTCAACGGATTTGGT-3' and reverse, 5'-CATGTG GGCCATGAGGTCCACCAC-3'.
Transfection. The log-phase prostate cancer cells $\left(1 \times 10^{5}\right.$ cells/well) were divided into groups, namely the control group, the negative control (NC) group and the miR-130b mimic group. Cells in the miR-130b mimic group were transfected with miR-130b mimic using Lipofectamine ${ }^{\circledR} 3000$ (Invitrogen; Thermo Fisher Scientific, Inc.), according to the manufacturer's protocol. Cells in the NC group were transfected with NC mimic. The control group was left untreated. After $72 \mathrm{~h}$ transfection, RT-qPCR was used to detect miR-130b expression in each group. miR-130b mimics and miR-130b NC were synthesized by Ribobio and the sequences used were as follow: hsa-miR-130b mimics, 5'-CAGUGCAAUGAUGAA AGGGCAU-3'; hsa-miR-130b NC, 5'-AUCCCCUUUCAU CAUUGCAUUG-3'.

Scratch wound assay. Cell migration was measured using a scratch wound assay. When cells reached $90 \%$ confluency, cells were digested and suspended at $5 \times 10^{5} \mathrm{cells} / \mathrm{ml}$. Thereafter, cells were seeded into 6 -well plates $\left(5 \times 10^{5}\right.$ cells/well $)$ for a monolayer culture. Cells were then scratched with a $10 \mu \mathrm{l}$ pipette tip (Thermo Fisher Scientific, Inc.). Cells were then incubated with RPMI-1640 medium supplemented with $10 \mathrm{~g} / 1$ bovine serum albumin (BSA; Gibco; Thermo Fisher Scientific, Inc.) and $1 \% \mathrm{FBS}$ for $24 \mathrm{~h}$. Thereafter, the cell migration rate was measured using a light microscope (magnification, x200; BioTek Instruments).

Transwell assay. Cell invasion was measured via Transwell assay with the $8.0 \mu \mathrm{m}$ pore size FluoroBlok membrane (Corning which was coated with BD Matrigel Matrix (Thermo Fisher Scientific, Inc.) in accordance with the manufacturer's protocol. Transfected cells were seeded $\left(3 \times 10^{3}\right.$ cells/well) in the upper chamber with serum-free medium. The lower chamber contained DMEM (Thermo Fisher Scientific, Inc.) with $10 \%$ FBS. After $48 \mathrm{~h}$ incubation, non-migrated cells were removed with a cotton swab. Invaded cells were fixed with $100 \%$ methanol at room temperature for $10 \mathrm{~min}$. Cells were then counted under a light microscope (x100 magnification; BioTek Instruments) in five predetermined fields. Each experiment was performed in triplicate.

Western blot analysis. Western blot analysis was used to determine protein levels. Protein samples were lysed using RIPA lysis buffer (Beyotime Institute of Biotechnology). The supernatant was retained in order to detect its protein concentration. Total protein was extracted by using a Total Protein Extraction kit (Phygene Life Sciences). Thereafter, $40 \mu \mathrm{g}$ protein was loaded onto a $10 \%$ SDS-PAGE gel. Proteins were then separated by electrophoresis and transferred to PVDF membranes (Sigma-Aldrich; Merck KGaA). The membrane was then blocked with 5\% skimmed milk in TBST for $1 \mathrm{~h}$ at room temperature. The membrane was then incubated overnight at $4^{\circ} \mathrm{C}$ with primary antibodies: DLL1 (cat. no. 2588; 1:1,000; Cell Signaling Technology, Inc.), phosphorylated (p)-PI3K (cat. no. 17366; 1:1,000; Cell Signaling Technology, Inc.), PI3K (cat. no. 4255; 1:1,000; Cell Signaling Technology, Inc.), p-Akt (cat. no. 4060; 1:2,000; Cell Signaling Technology, Inc.), Akt (cat. no. 9272; 1:1,000; Cell Signaling Technology, Inc.), GAPDH (cat. no. 5174; 1:1,000; Cell Signaling Technology, Inc.) and MMP9 (cat. no. 3852; 
Table I. Relationship between miR-130 and clinico-pathological parameters of patients with prostate cancer.

\begin{tabular}{|c|c|c|c|c|}
\hline Clinical features & Number & miR-130 high & miR-130 low & P-value \\
\hline Age (years) & & & & 0.201 \\
\hline$<50$ & 9 & 3 & 6 & \\
\hline$>50$ & 21 & 7 & 14 & \\
\hline Tumor size & & & & $0.004^{\mathrm{b}}$ \\
\hline$<3 \mathrm{~cm}$ & 13 & 8 & 5 & \\
\hline$>3 \mathrm{~cm}$ & 17 & 2 & 15 & \\
\hline Histological grade & & & & $0.018^{\mathrm{a}}$ \\
\hline Well-intermediately & 12 & 7 & 5 & \\
\hline Poor & 18 & 3 & 15 & \\
\hline Metastasis & & & & 0.166 \\
\hline No & 5 & 3 & 2 & \\
\hline Yes & 25 & 7 & 18 & \\
\hline
\end{tabular}

${ }^{\text {a }} \mathrm{P}<0.05$ and ${ }^{\mathrm{b}} \mathrm{P}<0.01$, miR-130 low group vs. miR-130 high group. miR, microRNA.

1:1,000; Cell Signaling Technology, Inc.). The membranes were then incubated with horseradish peroxidase-conjugated secondary antibodies (cat. no. 7074; 1:1,000; Cell Signaling Technology, Inc.) for $1 \mathrm{~h}$ at $37^{\circ} \mathrm{C}$. Protein bands were visualized using an enhanced chemiluminescence kit (ECL Prime Western Blotting Detection Reagent; GE Healthcare) and quantified using ImageJ software (Fiji version 1.8.0; National Institutes of Health).

Luciferase assay. The target of miR-130b was predicted via Online database TargetScan (http://www.targetscan. org/vert_72/). The 3'untranslated region (UTR) fragment of DLL1 containing mutant fragments was cloned into luciferase reporter vectors (Shanghai GeneChem Co., Ltd.). Prostate cancer cells were cultured in 96-well plates. miR-130b mimic (60 nM) or NC were co-transfected with $200 \mathrm{ng}$ of the 3'UTR wild-type (WT) or mutant (Mut) plasmid DNA into cells using Lipofectamine 3000 (Thermo Fisher Scientific, Inc.). Luciferase activity was measured and normalized to that of Renilla luciferase after $48 \mathrm{~h}$ using a Dual Luciferase Reporter Assay kit (Thermo Fisher Scientific, Inc.), according to manufacturer's protocol. All transfection assays were performed independently in triplicate.

Statistical analysis. Statistical analysis was performed using SPSS 19.0 software (IBM, Corp.). Data are presented as the mean \pm standard deviation. A Student's t-test (two-tailed) or a one-way analysis of variance followed by Dunnett's post-hoc test was used to analyze data. $\mathrm{P}<0.05$ was considered to indicate a statistically significant difference. All the experiments in the present study were conducted in triplicate.

\section{Results}

The expression of miR-130b and patients' clinical features. As shown in Table I, the expression of miR130b was significantly associated with tumor grades and size; however, there was no
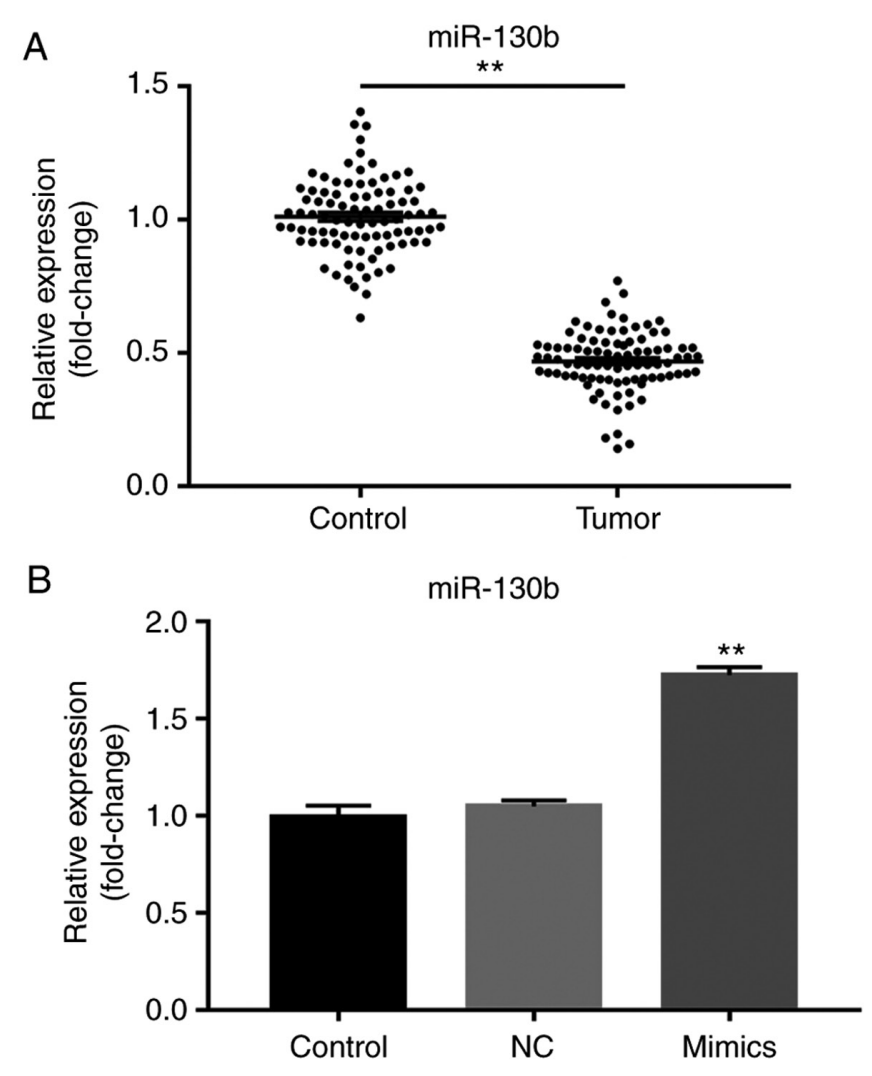

Figure 1. miR-130b is downregulated in prostate cancer. (A) miR-130b expression was significantly downregulated in tumor tissues in comparison to para-carcinoma tissue. (B) Transfection of prostate cancer cells with miR-130b mimics significantly increased miR-130b expression in comparison with the NC and control groups. Data are presented as the mean \pm standard deviation. ${ }^{* *} \mathrm{P}<0.01$ vs. NC group. miR, microRNA; NC, negative control.

significant correlation with the expression of miR-130 and patients' age, gender, and tumor metastasis.

Decreased miR-130b expression in prostate cancer tissue. RT-qPCR was used to determine miR-130b expression. The 

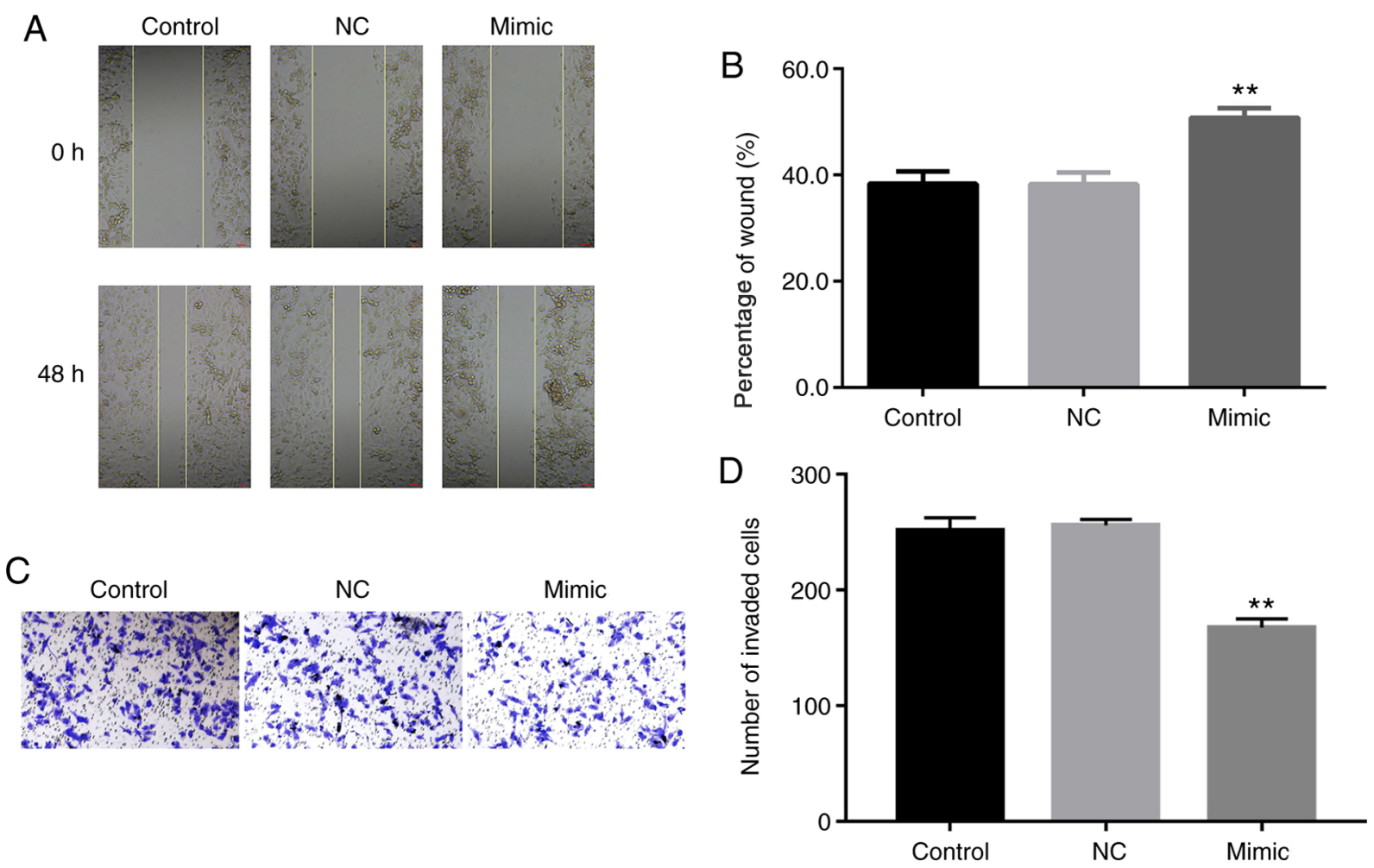

Figure 2. miR-130b inhibits the cell migration of prostate cancer cells. (A) A cell scratch wound assay and (B) analysis and (C) Transwell assays were performed to examine the effects of miR-130b on the migration potential in prostate cancer cells. In comparison to the non-control and control groups, prostate cancer cell migration was significantly decreased after miR-130b mimic treatment. (D) Cell invasion was significantly suppressed in the mimic group. Data are presented as the mean \pm standard deviation. ${ }^{* *} \mathrm{P}<0.01$ vs. NC group. miR, microRNA; NC, negative control.

A

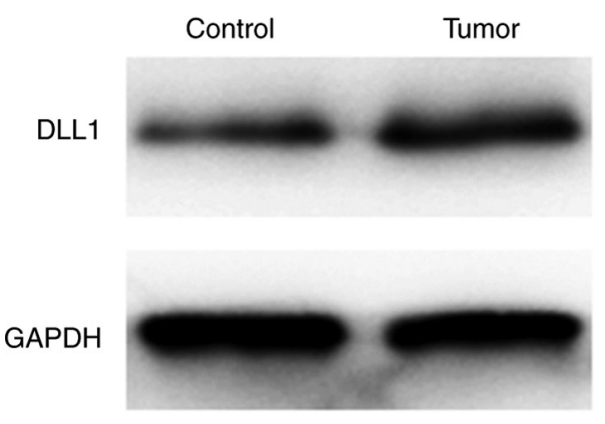

B

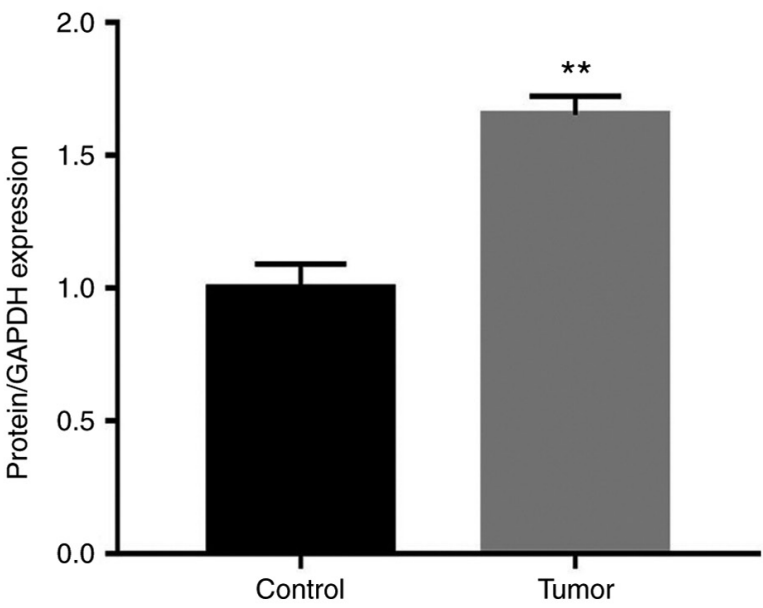

Figure 3. DLL1 expression is upregulated in prostate cancer. (A) Western blotting and (B) analysis of DLL1 expression. In prostate cancer cells, DLL1 expression level was significantly increased compared with the control group. Data are presented as the mean \pm standard deviation. ${ }^{* *} \mathrm{P}<0.01$, tumor group vs. control group. DLL, Delta-like 1.

results showed abnormally low miR-130b expression in tumor tissues compared with adjacent tissues $(\mathrm{P}<0.01$; Fig. 1A). Furthermore, in cells transfected with the miR-130b mimic, significantly increased miR-130b expression was observed compared with the $\mathrm{NC}$ and control groups $(\mathrm{P}<0.01$; Fig. 1B).

Impact of miR-130b on cell migration and invasion. Scratch wound and Transwell assays were used to estimate the effect of miR-130b on the migration of prostate cancer cells. Wound healing was significantly augmented post-miR-130b mimic treatment, suggesting that miR-130b suppressed the migration of prostate cancer cells $(\mathrm{P}<0.01$; Fig. $2 \mathrm{~A}$ and $\mathrm{B})$. Furthermore, the number of migrated cells treated with miR-130b mimic significantly decreased compared with the $\mathrm{NC}$ and control groups, thus proving that miR-130b significantly inhibited prostate cancer cell migration $(\mathrm{P}<0.01$; Fig. 2C and D).

DLL1 expression in prostate cancer. Western blot analysis was used to examine the DLL1 protein level. The results 

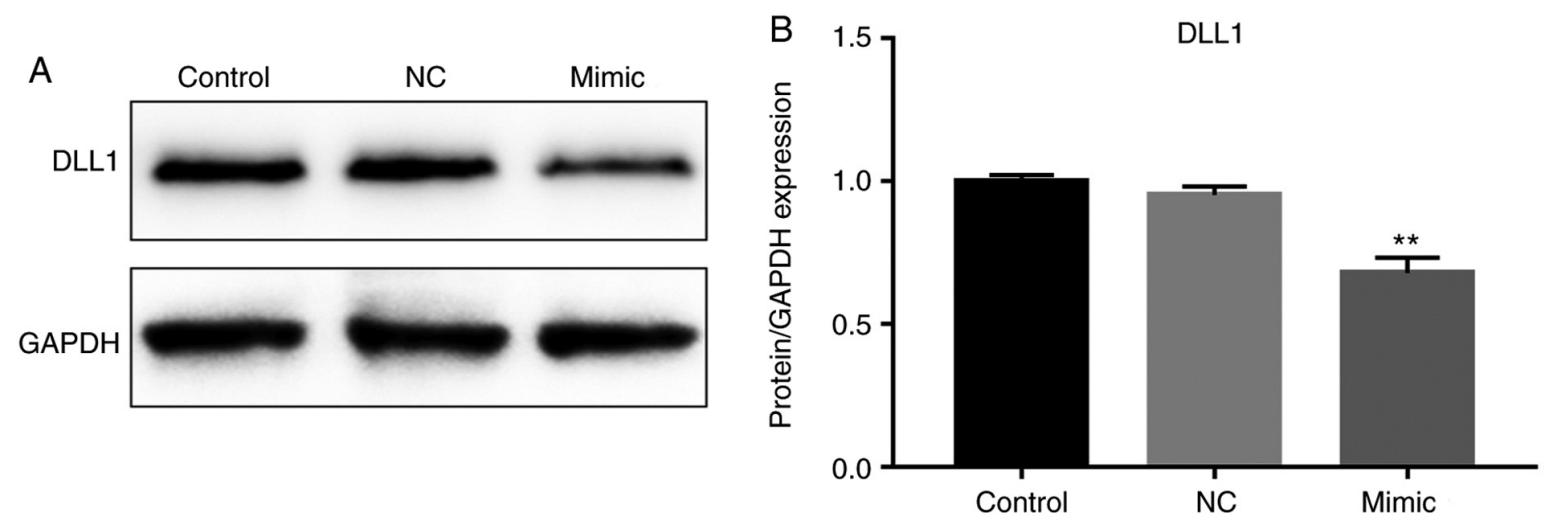

Figure 4. miR-130b inhibits the protein level of DLL1. (A) Western blotting and (B) analysis of DLL1 expression. The protein level of DLL1 treated with miR-130b mimic was significantly decreased compared with the non-control and control groups. Data are presented as the mean \pm standard deviation. ${ }^{* *} \mathrm{P}<0.01$, mimic group vs. NC group. miR, microRNA; DLL, Delta-like 1; NC, negative control.

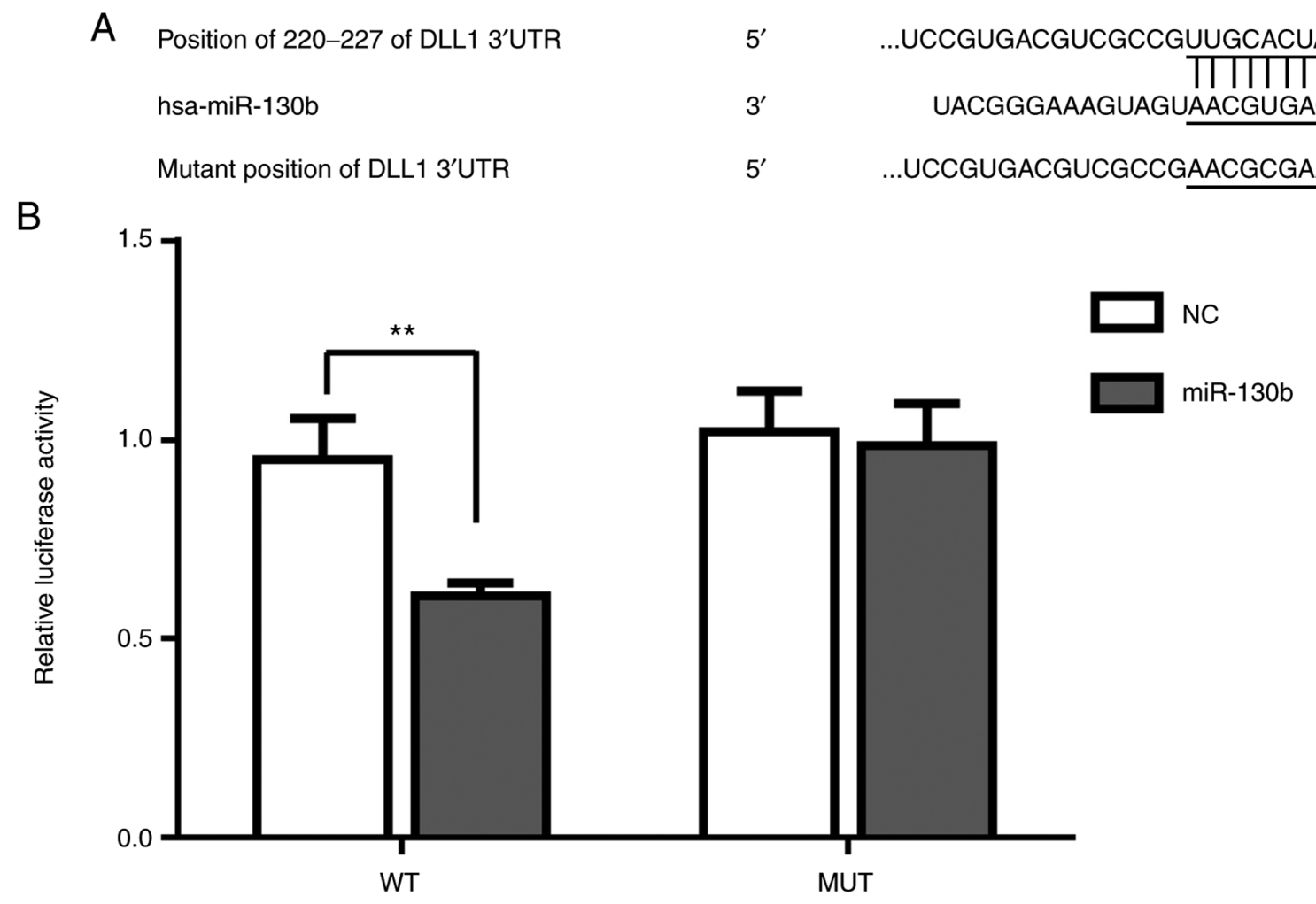

Figure 5. miR-130b may regulate DLL1 mRNA stability by directly targeting the 3'UTR in prostate cancer cells. (A) The possible binding site of miR-130b and DLL1 was predicted by TargetScan 7.2. (B) The luciferase activity of the WT of DLL1 was significantly decreased after the transfection with the miR-130b mimic, while there was no significant difference between the non-control and miR-130b mimic groups cloned with MUT DLL1. Data are presented as the mean \pm standard deviation. "* P<0.01. miR, microRNA; DLL, Delta-like 1; UTR, untranslated region; MUT, mutant; WT, wild type; NC, negative control.

showed that the DLL1 protein expression level in prostate cancer tissues was increased compared with in normal adjacent tissues $(\mathrm{P}<0.01$; Fig. 3).

miR-130b inhibits the protein level of DLL1. The DLL1 protein level in cells treated with miR-130b mimics was significantly decreased compared with in the $\mathrm{NC}$ and control groups ( $\mathrm{P}<0.01$; Fig. 4).

miR-130b targets DLL1. Online software (TargetScan) suggested that DLL1 was a target gene of miR-130b (http://www.targetscan.org/vert_72/) (Fig. 5A). The results of the luciferase assay suggested that relative luciferase activity of WT DLL1 was significantly reduced after miR-130b mimic treatment $(\mathrm{P}<0.01)$, while the luciferase activity of Mut DLL1 in the $\mathrm{NC}$ and miR-130b mimic groups showed no significant difference (Fig. 5B), thus proving that DLL1 was the direct target of miR-130b.

miR-130b suppresses the mRNA level of PI3K, AKT, MMP9 and DLL1 expression. The RT-qPCR results showed that the mRNA expression of PI3K, AKT, MMP9 and DLL1 was significantly downregulated after miR-130b mimic treatment $(\mathrm{P}<0.01$; Fig. 6). 

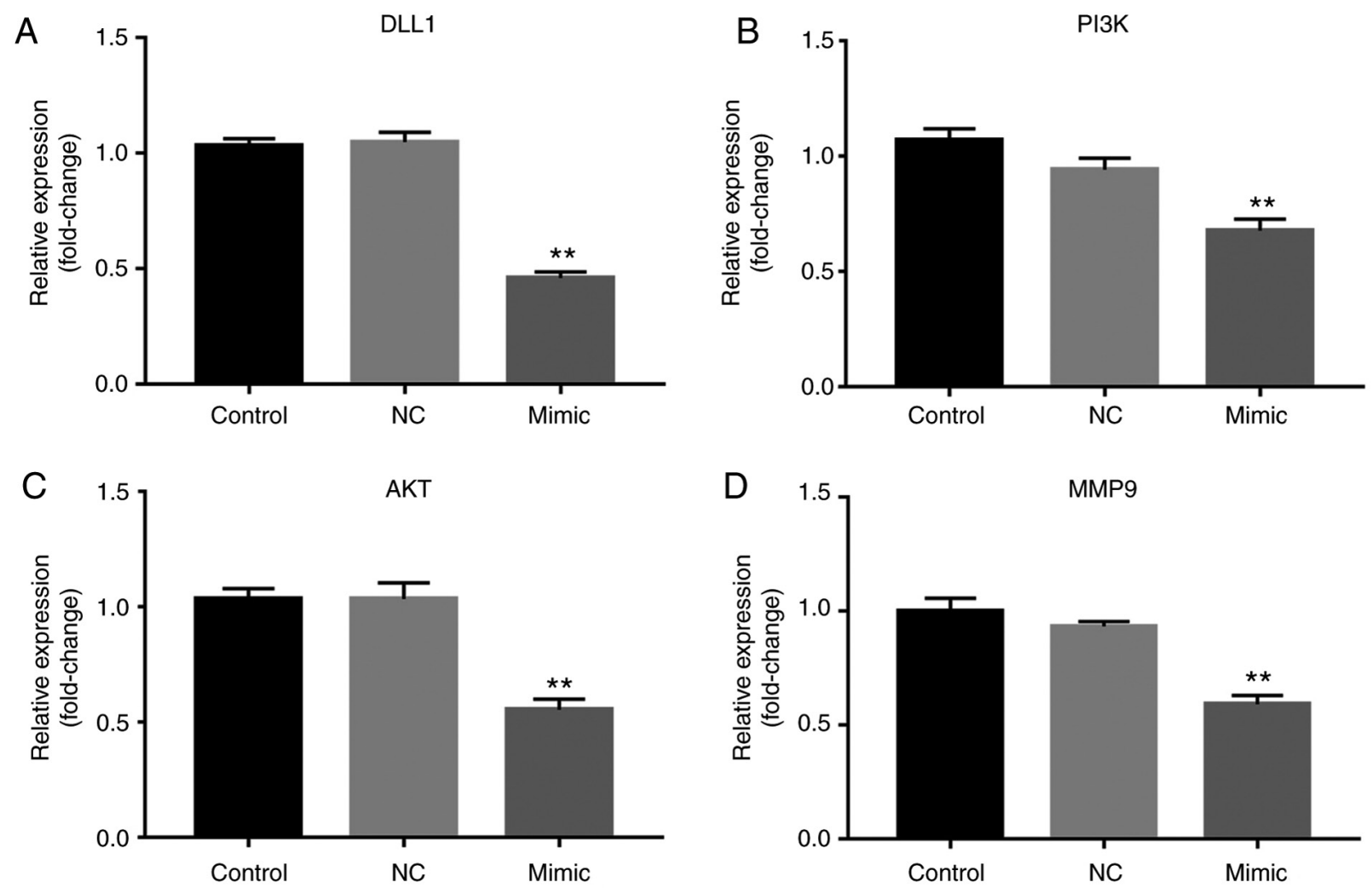

Figure 6. miR-130b inhibits the mRNA level of the PI3K/Akt signaling pathway and MMP9 expression. The mRNA expression levels of (A) DLL1, (B) PI3K, (C) Akt and (D) MMP9 were significantly decreased after miR-130b treatment, compared with those of the non-control and control groups. Data are presented as the mean \pm standard deviation. ${ }^{* *} \mathrm{P}<0.01$, mimic group vs. NC group. p-AKT, phosphorylated-protein kinase B; MMP9, matrix metalloproteinase-9; miR, microRNA; PI3K, phosphatidylinositol 3 kinase; DLL, Delta-like 1.
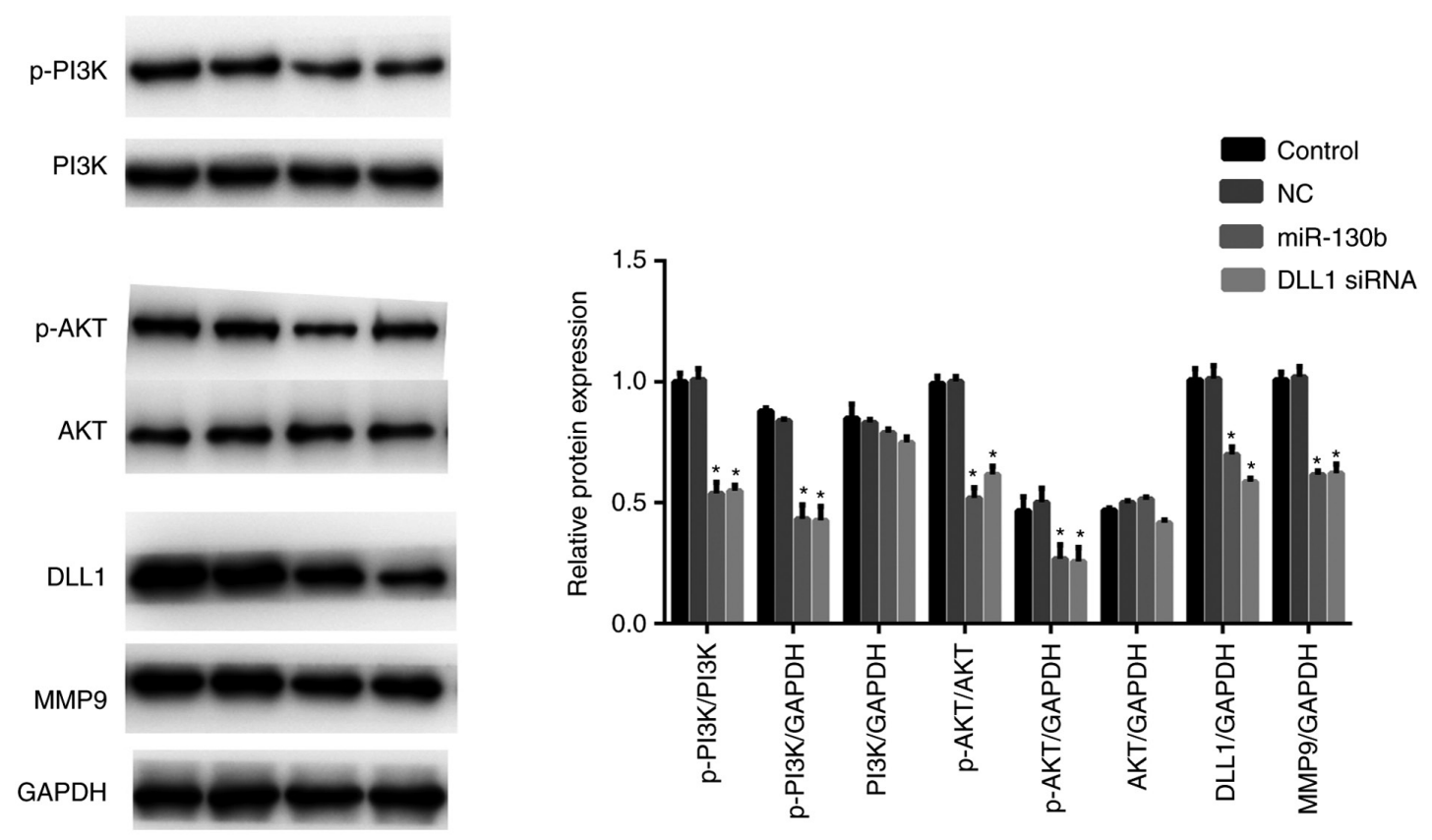

Figure 7. miR-130b downregulates the protein level of p-PI3K, p-AKT, MMP9 and DLL1. miR-130b mimic or DLL1 siRNA significantly decreased the protein level of p-PI3K, p-AKT, MMP9 and DLL1. Data are presented as the mean \pm standard deviation. ${ }^{*} \mathrm{P}<0.05$, mimic group vs. NC group. $\mathrm{p}$-AKT, phosphorylated-protein kinase B; MMP9, matrix metalloproteinase-9; miR, microRNA; PI3K, phosphatidylinositol 3 kinase; DLL, Delta-like 1.

miR-130b suppresses the mRNA level of $p$-PI3K, $p-A K T, M M P 9$ and DLL1. Protein levels of p-PI3K, p-AKT, MMP9 and DLL1 were then checked. The results showed that miR-130b mimic or
DLL1 siRNA significantly decreased p-PI3K, p-AKT, MMP9 and DLL1 protein levels relative to GAPDH while there were no significant differences in PI $3 \mathrm{~K}$ and AKT levels ( $\mathrm{P}<0.01$; Fig. 7). 


\section{Discussion}

Paralogous miRNA sequences of the miR130 family, miR-130a and miR-130b are situated on chromosomes 11 and 22, respectively (26-28). miR-130b inhibits cell proliferation and induces apoptosis in gastric cancer cells by targeting CYLD (29). Moreover, miR-130b is upregulated in triple-negative breast cancer and participates in its progression (30). Furthermore, miR-130b inhibits the cell proliferation and invasion of pancreatic cancer by targeting signal transducer and activator of transcription 3 (31). By contrast, overexpression of miR-130b promotes cell proliferation in esophageal squamous cell carcinoma (32) and in hepatocellular carcinoma (33). The roles of miR-130b vary across cancer types. However, evidence for the function of miR-130b in prostate cancer is not clear. In the present study, it was found that the expression of miR-130b was suppressed in prostate cancer tissues. It was also suggested that miR-130b may act as an antitumor gene in prostate cancer. To fully understand the role of miR-130b in prostate cancer, scratch wound and Transwell assays were performed, the results of which suggested that miR-130b inhibited the migration and invasion rates of prostate cancer cells.

To understand the mechanisms underlying the regulatory effect of miR-130b on the migration and invasion of prostate cancer cells, the present study investigated the possible target genes of miR-130b. It was identified that miR-130b may directly target DLL1. DLL1 expression was suppressed in the miR-130b mimic group. Furthermore, downregulated expression of DLL1 promotes lateral motility of PC-3 cells (16). DLL1-activated Notch1 stimulates C4-2B differentiation (34). Therefore, it was concluded that miR-130b may affect prostate cancer cell migration and invasion by targeting DLL1.

To further understand the potential mechanisms of miR-130b in prostate cancer, the present study assessed related pathways. The PI3K/Akt/mTOR signaling pathway is one of the most abnormal pathways in human cancer. PI3K/Akt/mTOR plays a role in controlling the migration and invasion of glioblastoma cells (35). Key gene mutations, such as PI3K, PTEN, Akt, TSC, LKB and mTOR may lead to the abnormal activation of certain pathways including PI3K/Akt, thus resulting in tumorigenesis (36). Akt is the switching locus for the cancer phenotype and a key factor in the downstream regulation of PI3K (37). Previous studies have shown that the PI3K/Akt pathway plays a crucial role in the migration and invasion of prostate cancer cells (38-40). PI3K/Akt expression was increased post-DLL1 treatment (41). Moreover, previous studies revealed that miR-130b mediates the progression of breast cancer and epithelial ovarian cancer via regulating the PI3K/Akt and MMP9 signaling pathway $(42,43)$. In the present study, it was shown that miR-130b downregulated PI3K/Akt expression. miR-130b mimic significantly inhibited PI3K/Akt expression, thus restricting migration and invasion abilities. Moreover, knockout of DLL1 inhibited the expression of p-PI3K/Akt. Therefore, the inhibition of the PI3K/Akt pathway may be important in tumor treatment.

MMPs are family members of extracellular proteinases that regulate cellular biological processes, including cell proliferation, invasion and migration. MMPs are best known for their role in the degradation and removal of extracellular matrix molecules (44). Therefore, MMP expression was shown to be related to the invasive ability of prostate cancer. DLL1 and MMP9 play an important role in breast cancer cell invasion (45). The present study showed that miR-130b and knockdown of DLL1 suppressed MMP9 activity. This finding was consistent with previous studies (46-49).

However, there are some limitations in this study. Firstly, an miRNA may have several targets and a gene may be targeted by several miRNAs. Secondly, the present study was limited to the number of participants enrolled and lack of in vivo study. Although PI3K, Akt and MMP9 were suppressed in the mimic group, the current study did not confirm these molecules were a target of miR-130b directly or indirectly. Moreover, the use of $1 \%$ FBS in wound healing assays is also a limitation of the study.

In conclusion, the present study identified a novel pathway, interlinking PI3K/Akt, miR-130b, DLL1 and MMP9, p-Akt and $\mathrm{p}-\mathrm{PI} 3 \mathrm{~K}$, which regulates the migration and invasion of prostate cancer cells. It was found that miR-130b expression in prostate cancer was decreased. Furthermore, miR-130b reduced the migration of prostate cancer cells by targeting DLL1 and inhibiting the PI3K/Akt and MMP9 pathways. These findings provide an intriguing biomarker and treatment strategy for patients with prostate cancer.

\section{Acknowledgements}

Not applicable.

\section{Funding}

No funding was received.

\section{Availability of data and materials}

The datasets used and/or analyzed during the current study are available from the corresponding author on reasonable request.

\section{Authors' contributions}

LiJ was involved in the preparation of the manuscript and worked with $\mathrm{BL}$ and $\mathrm{HG}$ to perform the experiments and collect the data; and cooperated with LinJ, DL and JH to interpret the data. LinJ and BJ were responsible for design of this study. LiJ and BJ confirm the authenticity of all the raw data. All authors have read and approved the final manuscript.

\section{Ethics approval and consent to participate}

Informed consent was obtained from all patients and the study was approved by Yulin Traditional Chinese Medicine Hospital Yulin.

\section{Patient consent for publication}

Not applicable.

\section{Competing interests}

The authors declare that they have no competing interests. 


\section{References}

1. Chen DQ, Yu C, Zhang XF, Liu ZF, Wang R, Jiang M, Chen H, Yan F, Tao M, Chen LB, et al: HDAC3-mediated silencing of miR-451 decreases chemosensitivity of patients with metastatic castration-resistant prostate cancer by targeting NEDD9. Ther Adv Med Oncol 10: 1758835918783132, 2018.

2. Siegel RL, Miller KD and Jemal A: Cancer statistics, 2017. CA Cancer J Clin 67: 7-30, 2017.

3. Zhu JG, Pan C, Jiang J, Deng M, Gao H, Men B, McClelland M, Mercola D, Zhong WD and Jia Z: Six stroma-based RNA markers diagnostic for prostate cancer in European-Americans validated at the RNA and protein levels in patients in China. Oncotarget 6 : 16757-16765, 2015.

4. Paliouras AR, Monteverde T and Garofalo M: Oncogene-induced regulation of microrna expression: Implications for cancer initiation, progression and therapy. Cancer Lett 421: 152-160, 2018

5. Zhang C, Qian D, Zhao H, Lv N, Yu P and Sun Z: miR-17 improves insulin sensitivity through inhibiting expression of ASK1 and anti-inflammation of macrophages. Biomed Pharmacother 100 448-454, 2018

6. Bartel DP: MicroRNAs: Genomics, biogenesis, mechanism, and function. Cell 116: 281-297, 2004.

7. Wu N, Han Y, Liu H, Jiang M, Chu Y, Cao J, Lin J, Liu Y, Xu B and Xie X: miR-5590-3p inhibited tumor growth in gastric cancer by targeting DDX5/AKT/m-TOR pathway. Biochem Biophys Res Commun 503: 1491-1497, 2018.

8. Sun L, Guo Z, Sun J, Li J, Dong Z, Zhang Y, Chen J, Kan Q and Yu Z: MiR-133a acts as an anti-oncogene in Hepatocellular carcinoma by inhibiting FOSL 2 through TGF- $\beta / S m a d 3$ signaling pathway. Biomed Pharmacother 107: 168-176, 2018.

9. Kaalund SS, Venø MT, Bak M, Møller RS, Laursen H, Madsen F, Broholm H, Quistorff B, Uldall P, Tommerup N, et al: Aberrant expression of mir-218 and mir-204 in human mesial temporal lobe epilepsy and hippocampal sclerosis-convergence on axonal guidance. Epilepsia 55: 2017-2027, 2014.

10. Shen J and Li M: Microrna-744 inhibits cellular proliferation and invasion of colorectal cancer by directly targeting oncogene notch1. Oncol Res: Feb 22, 2018 (Epub ahead of print). doi: 10.3 727/096504018X15188747585738.

11. Chen Q, Zhao X, Zhang H, Yuan H, Zhu M, Sun Q, Lai X, Wang Y, Huang J, Yan J and Yu J: miR-130b suppresses prostate cancer metastasis through down-regulation of MMP2. Mol Carcinog 54: 1292-1300, 2015.

12. Zhang JP, Li N, Bai WZ, Qiu XC, Ma BA, Zhou Y, Fan QY and Shan LQ: Notch ligand Delta-like 1 promotes the metastasis of melanoma by enhancing tumor adhesion. Braz J Med Biol Res 47: 299-306, 2014.

13. Pang RT, Leung CO, Lee CL, Lam KK, Ye TM, Chiu PC and Yeung WS: MicroRNA-34a is a tumor suppressor in choriocarcinoma via regulation of Delta-like1. BMC Cancer 13: 25, 2013

14. Yu F, Hao X, Zhao H, Ge C, Yao M, Yang S and Li J: Delta-like 1 contributes to cell growth by increasing the interferon-inducible protein 16 expression in hepatocellular carcinoma. Liver Int 30 : 703-714, 2010

15. Purow BW, Haque RM, Noel MW, Su Q, Burdick MJ, Lee J, Sundaresan T, Pastorino S, Park JK, Mikolaenko I, et al: Expression of notch-1 and its ligands, delta-like-1 and jagged-1, is critical for glioma cell survival and proliferation. Cancer Res 65: 2353-2363, 2005.

16. Scorey N, Fraser SP, Patel P, Pridgeon C, Dallman MJ and Djamgoz MB: Notch signalling and voltage-gated $\mathrm{Na}+$ channel activity in human prostate cancer cells: Independent modulation of in vitro motility. Prostate Cancer Prostatic Dis 9: 399-406, 2006.

17. Adimonye A, Stankiewicz E, Kudahetti S, Trevisan G, Tinwell B, Corbishley C, Lu YJ, Watkin N and Berney D: Analysis of the pi3k-Akt-mtor pathway in penile cancer: Evaluation of a therapeutically targetable pathway. Oncotarget 9: 16074-16086, 2018.

18. Cretella D, Ravelli A, Fumarola C, La Monica S, Digiacomo G Cavazzoni A, Alfieri R, Biondi A, Generali D, Bonelli M and Petronini PG: The anti-tumor efficacy of cdk4/6 inhibition is enhanced by the combination with pi3k/Akt/mtor inhibitors through impairment of glucose metabolism in tnbc cells. J Exp Clin Cancer Res 37: 72, 2018.

19. Li H, Xu W, Ma Y, Zhou S and Xiao R: Milk fat globule membrane protein promotes $\mathrm{c} 2 \mathrm{c} 12$ cell proliferation through the pi3k/Akt signaling pathway. Int J Biol Macromol 114: 1305-1314 2018.
20. Hassan M, Watari H, AbuAlmaaty A, Ohba Y and Sakuragi N Apoptosis and molecular targeting therapy in cancer. Biomed Res Int 2014: 150845, 2014

21. Shi X, Yang L, Xie J, Zhao Y, Cong J, Li Z, Li H, Cheng X and Fan J: UNBS5162 inhibits proliferation of human melanoma cells by inducing apoptosis via the PI3K/Akt pathway. Mol Med Rep 18: 3382-3388, 2018.

22. Zhang XR, Wang SY, Sun W and Wei C: Isoliquiritigenin inhibits proliferation and metastasis of MKN28 gastric cancer cells by suppressing the PI3K/AKT/mTOR signaling pathway. Mol Med Rep 18: 3429-3436, 2018.

23. Paplomata E and O'Regan R: The PI3K/AKT/mTOR pathway in breast cancer: Targets, trials and biomarkers. Ther Adv Med Oncol 6: 154-166, 2014.

24. Wang HY, Zhang CY, Xu LT, Zang K, Ning ZY, Jiang F, Chi HY, Zhu XY and Meng ZQ: Bufalin suppressed hepatocellular carcinoma invasion and metastasis by targeting HIF-1 $\alpha$ via the PI3K/AKT/mTOR pathway. Oncotarget 7: 320193-20208, 2016.

25. Livak KJ and Schmittgen TD: Analysis of relative gene expression data using real-time quantitative PCR and the 2(-Delta Delta C(T)) method. Methods 25: 402-408, 2001.

26. Chen Y, Zhao F, Cui D, Jiang R, Chen J, Huang Q and Shi J: Hoxd-as1/mir-130a sponge regulates glioma development by targeting e2f8. Int J Cancer 142: 2313-2322, 2018.

27. Tang C, Yang Z, Chen D, Xie Q, Peng T, Wu J and Qi S: Downregulation of mir-130a promotes cell growth and epithelial to mesenchymal transition by activating hmgb2 in glioma. Int J Biochem Cell Biol 93: 25-31, 2017.

28. Wei H, Cui R, Bahr J, Zanesi N, Luo Z, Meng W, Liang G and Croce CM: Mir-130a deregulates pten and stimulates tumor growth. Cancer Res 77: 6168-6178, 2017.

29. Chen H, Yang Y, Wang J, Shen D, Zhao J and Yu Q: miR-130b-5p promotes proliferation, migration and invasion of gastric cancer cells via targeting RASAL1. Oncol Lett 15: 6361-6367, 2018.

30. Zhang HD, Jiang LH, Sun DW, Li J and Ji ZL: The role of mir-130a in cancer. Breast Cancer 24: 521-527, 2017.

31. Zhao G, Zhang JG, Shi Y, Qin Q, Liu Y, Wang B, Tian K, Deng SC, Li X, Zhu S, et al: miR-130b is a prognostic marker and inhibits cell proliferation and invasion in pancreatic cancer through targeting STAT3. PLoS One 8: e73803, 2013.

32. Yu T, Cao R, Li S, Fu M, Ren L, Chen W, Zhu H, Zhan Q and Shi R: Mir-130b plays an oncogenic role by repressing PTEN expression in esophageal squamous cell carcinoma cells. BMC cancer 15: 29, 2015.

33. Chang RM, Xu JF, Fang F, Yang H and Yang LY: Microrna-130b promotes proliferation and emt-induced metastasis via pten/p-Akt/hif-1alpha signaling. Tumour Biol 37: 10609-10619, 2016.

34. Zayzafoon M, Abdulkadir SA and McDonald JM: Notch signaling and ERK activation are important for the osteomimetic properties of prostate cancer bone metastatic cell lines. J Biol Chem 279: 3662-3670, 2004.

35. Carmen M, Ileana G, Stefano B, Oxana B, Bernard F, Carlo R, Rosario D and Cataldo A: PP242 counteracts glioblastoma cell proliferation, migration, invasiveness and stemness properties by inhibiting mTORC2/AKT. Front Cell Neurosci 12: 99, 2018

36. Slattery ML, Herrick JS, Lundgreen A, Fitzpatrick FA, Curtin K and Wolff RK: Genetic variation in a metabolic signaling pathway and colon and rectal cancer risk: mTOR, PTEN, STK11, RPKAA1, PRKAG2, TSC1, TSC2, PI3K and Akt1. Carcinogenesis 31: 1604-1611, 2010

37. Sun DM, Tang BF, Li ZX, Guo HB, Cheng JL, Song PP and Zhao X: miR-29c reduces the cisplatin resistance of non-small cell lung cancer cells by negatively regulating the PI3K/Akt pathway. Sci Rep 8: 8007, 2018

38. Zhou Y, Gu P, Li J, Li F, Zhu J, Gao P, Zang Y, Wang Y, Shan Y and Yang D: Suppression of STIM1 inhibits the migration and invasion of human prostate cancer cells and is associated with PI3K/Akt signaling inactivation. Oncol Rep 38: 2629-2636, 2017.

39. Xu S, Ge J, Zhang Z and Zhou W: miR-129 inhibits cell proliferation and metastasis by targeting ETS1 via PI3K/AKT/mTOR pathway in prostate cancer. Biomed Pharmacother 96: 634-641, 2017.

40. Dhupkar P, Zhao H, Mujoo K, An Z and Zhang N: Crk II silencing down-regulates IGF-IR and inhibits migration and invasion of prostate cancer cells. Biochem Biophys Rep 8: 382-388, 2016.

41. Zhang W, Hsu P, Zhong B, Guo S, Zhang C, Wang Y, Luo C, Zhan Y and Zhang C: MiR-34a enhances chondrocyte apoptosis, senescence and facilitates development of osteoarthritis by targeting DLL1 and regulating PI3K/AKT pathway. Cell Physiol Biochem 48: 1304-1316, 2018. 
42. Miao Y, Zheng W, Li N, Su Z, Zhao L, Zhou H and Jia L: MicroRNA-130b targets PTEN to mediate drug resistance and proliferation of breast cancer cells via the PI3K/Akt signaling pathway. Sci Rep 7: 41942, 2017.

43. Zhou D, Zhang L, Sun W, Guan W, Lin Q, Ren W, Zhang J and $\mathrm{Xu}$ G: Cytidine monophosphate kinase is inhibited by the TGF- $\beta$ signalling pathway through the upregulation of miR-130b-3p in human epithelial ovarian cancer. Cell Signal 35: 197-207, 2017.

44. Elizabeth IH, Emma FS and Stack MS: With great age comes great metastatic ability: Ovarian cancer and the appeal of the aging peritoneal microenvironment. Cancers (Basel) 10: 230, 2018.

45. Shui Y, Yu X, Duan R, Bao Q, Wu J, Yuan H and Ma C: miR-130b-3p inhibits cell invasion and migration by targeting the Notch ligand Delta-like 1 in breast carcinoma. Gene 609: 80-87, 2017.

46. Duellman T, Chen X, Wakamiya R and Yang J: Nucleic acid-induced potentiation of matrix metalloproteinase-9 enzymatic activity. Biochem J 475: 1597-1610, 2018.
47. Murawala H, Patel S, Ranadive I, Desai I and Balakrishnan S: Variation in expression and activity pattern of $\mathrm{mmp} 2$ and $\mathrm{mmp} 9$ on different time scales in the regenerating caudal fin of poecilia latipinna. J Fish Biol 92: 1604-1619, 2018.

48. Sahay AS, Jadhav AT, Sundrani DP, Wagh GN, Mehendale SS and Joshi SR: Matrix metalloproteinases-2 (mmp-2) and matrix metalloproteinases-9 (mmp-9) are differentially expressed in different regions of normal and preeclampsia placentae. J Cell Biochem 119: 6657-6664, 2018.

49. Weiler J, Mohr M, Zänker KS and Dittmar T: Matrix metalloproteinase-9 (mmp9) is involved in the tnf-alpha-induced fusion of human m13sv1-cre breast epithelial cells and human mda-mb-435-pfdrl cancer cells. Cell Commun Signal 16: 14, 2018.

This work is licensed under a Creative Commons Attribution-NonCommercial-NoDerivatives 4.0 International (CC BY-NC-ND 4.0) License. 